Article

\title{
Organic Fluorescent Compounds that Display Efficient Aggregation-Induced Emission Enhancement and Intramolecular Charge Transfer
}

\author{
Ruibin Hou ${ }^{1,2}$ (D), Baohua Zhao ${ }^{1}$, Yan Xia ${ }^{1,2, *}$ and Dongfeng $\mathrm{Li}^{1, *}$ \\ 1 School of Chemistry and Life Science, Changchun University of Technology, Changchun 130012, China; \\ hrb1018@163.com (R.H.); zbh1969@126.com (B.Z.) \\ 2 Advanced Institute of Materials Science, Changchun University of Technology, Changchun 130012, China \\ * Correspondence: hmz20130521@163.com (Y.X.); lidongfeng@mail.ccut.edu.cn (D.L.); \\ Tel.: +86-431-8571-6671 (Y.X.); +86-431-8571-6671 (D.L.)
}

Academic Editor: Jwo-Huei Jou

Received: 29 May 2018; Accepted: 8 June 2018; Published: 14 June 2018

\begin{abstract}
A series of symmetric sulfone-linked organic fluorescent compounds (1a-c) was synthesized and characterized. V-shaped 1a-c were designed as aggregate of intramolecular charge transfer (ICT) and aggregation-induced emission enhancement (AIEE) processes. The 1a-c emitted intense blue violet lights in normal solvents. A large red shift of the emission wavelength and dramatic decrease of emission efficiency occurred with increasing solvent polarity. The 1a-c will function well as electron transport and blue light-emitting materials through theoretical calculations.
\end{abstract}

Keywords: 1,3,4-oxadiazole; aggregation-induced emission enhancement; blue light-emitting material

\section{Introduction}

Fluorescent organic molecules are widely used as active elements in organic light-emitting diodes (OLED), chemosensors, and bioprobes [1-5]. However, although most of these fluorescent organic molecules possess planar conjugated structures and display reasonable emission in dilute solutions, their emission is weak or nonexistent in the solid state because of aggregation-caused quenching. Such quenching limits the applications of fluorescent organic molecules [6-8]. Recently, multiple groups have independently reported an interesting phenomenon called aggregation-induced emission (AIE), wherein aggregated molecules emit more intense fluorescence than their dilute solutions [9-11]. Propeller-shaped molecules such as hexaphenylsilole, tetraphenylethene, and quinoline-malononitrile and their derivatives are known for their unique ability to promote AIE [12].

The integration of AIE and intramolecular charge transfer (ICT) into one molecule has attracted much attention. This type of luminophore can emit strong fluorescence not only in the aggregated form or solid state but also in dilute solution [13-15]. For example, Tang and coworkers developed a new donor (D)-acceptor (A) system that exhibits dual photoluminescence (PL) activity, including ICT and AIE [16]. However, the integration of AIE and ICT into one molecule is still rare and poorly understood, and thus warrants further study to clarify the relationship between molecular structure and optical properties.

Herein, we report a series of new V-shaped D- $\pi-A-\pi-D$ fluorophores $(\mathbf{1 a}-\mathbf{c})$ that exhibit strong blue emission in both solution (nonpolar solvents) and the solid state. We integrated a sulfone into 1a-c because it has been demonstrated that sulfones possess a special V-shaped structure, which is helpful to weaken $\pi-\pi$ stacking. A 1,3,4-oxadiazole was also included in $\mathbf{1 a - c}$ because it is an attractive electron-accepting material that has received considerable interest for use in OLEDs. 


\section{Results and Discussion}

\subsection{Synthesis of Target Compounds $\mathbf{1 a - c}$}

The synthetic routes to $\mathbf{1 a}-\mathbf{c}$ are described in Scheme 1 . The intermediate $\mathrm{p}, \mathrm{p}^{\prime}$-dihydrazinocarbonyl diphenylsulfone (4) was synthesized according to a previous report [13]. The target compounds 1a-c were obtained by condensation reactions between intermediate 4 and 4-alkoxybenzoic acid in phosphoryl chloride under reflux. Compounds 1a-c were all white crystals and their yields ranged from $37 \%$ to $43 \%$. The structures of $1 \mathbf{a}-\mathbf{c}$ were characterized by ${ }^{1} \mathrm{H}$ and ${ }^{13} \mathrm{C}-\mathrm{NMR}$ spectroscopy, mass spectrometry, and elemental analysis.
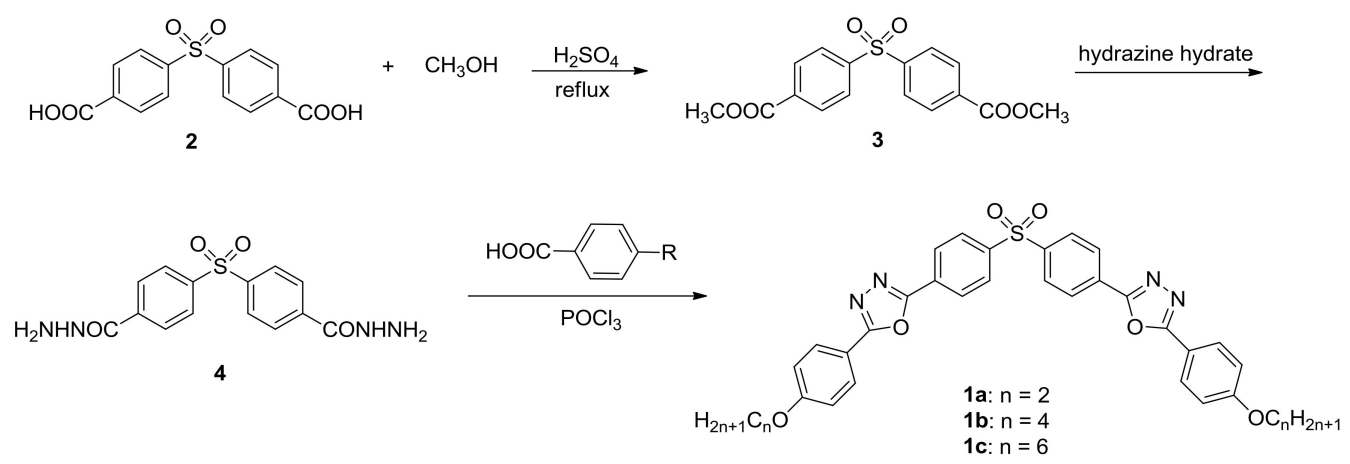

Scheme 1. Synthetic route to $1 \mathrm{a}-\mathrm{c}$.

\subsection{The Optical Properties of Compounds $\mathbf{1 a}-\mathbf{c}$}

The optical properties of $\mathbf{1 a - c}$ in solution and the solid state were investigated by UV-vis absorption and PL spectroscopies. The data revealed that the alkyl chain did not influence the properties of these compounds. Figure S5 presents the UV-vis absorption spectra of the same concentration of $\mathbf{1 a}-\mathbf{c}$ in different solvents. The absorption maxima $\left(\lambda_{\mathrm{ab}}\right)$ exhibit a slight red shift of a few nanometers with increasing solvent polarity. In contrast, the PL maxima of 1a-c vary dramatically with changes in solvent polarity, as shown in Figure 1 and Figure S6. The PL intensity gradually decreased with increasing solvent polarity and fluorescent quantum yields $\left(\mathrm{Q}_{\mathrm{ys}}\right)$ decreased from 0.42 to 0.05 when the solvent was changed from toluene to DMSO. Emission maxima $\left(\lambda_{\mathrm{em}}\right)$ red-shifted from $387 \mathrm{~nm}$ in toluene to $468 \mathrm{~nm}$ in DMSO. The red shift and decreased QY can be ascribed to stabilization of the excited state. This behavior originates from the strong ICT character from the alkoxyl benzene to the sulfone. This result indicates that the ICT excited state has a larger dipole moment than the ground state, which is caused by substantial charge redistribution. Because of the dipole-dipole interaction of a polar solvent and excited state, the ICT state is more stable in a polar solvent than in a nonpolar one.

To determine whether 1a-c are AIE-active, fluorescence emission spectra of their diluted mixtures in THF/water and DMF/water mixtures with different water fractions $\left(f_{\mathrm{W}}\right)$ were measured (Figure 2 and Figure S7). Figure 2 reveals that 1a in pure THF solution emitted intense indigo blue fluorescence at $427 \mathrm{~nm}$, which was dramatically quenched when a small amount of water was added, as evidenced by its weak emission in the THF/water mixtures with $f_{\mathrm{w}} \leq 40 \mathrm{vol} \%$. Meanwhile, $\lambda_{\mathrm{em}}$ red-shifted to about $449 \mathrm{~nm}$ upon addition of water, which was mainly attributed to the increase of solvent polarity and enhancement of the ICT effect. If a hydrophobic environment was created inside the aggregates, the ICT effect should be alleviated, and the fluorescence should recover because of the AIE effect. The pure DMF solution of 1a displayed weak blue fluorescence at $\lambda_{\mathrm{em}}=458 \mathrm{~nm}$. When $f_{\mathrm{w}}$ of the DMF/water mixture was low, $\lambda_{\mathrm{em}}$ of $\mathbf{1 a}$ was dramatically quenched and slightly blue-shifted. When $f_{\mathrm{w}}$ of the DMF/water mixture was high, $\lambda_{\mathrm{em}}$ of $\mathbf{1 a}$ was red-shifted and the fluorescence intensity did not recover. In this case, the solvent polarity influences the AIE effect. These data illustrate our 
speculation that 1a is a luminogen with both ICT and AIE characteristics. Both $\mathbf{1 b}$ and $\mathbf{1 c}$ exhibited similar AIE effects, as shown in Figure S7.

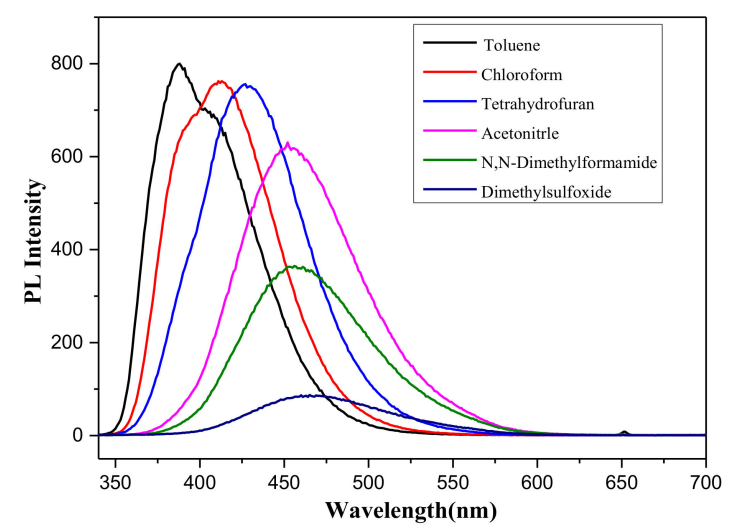

Figure 1. PL emission spectra of $1 \mathrm{a}$ in different solutions at the same concentration $\left(10^{-5} \mathrm{~mol} / \mathrm{L}^{-1}\right.$, excitation wavelength: $322 \mathrm{~nm}$ ).
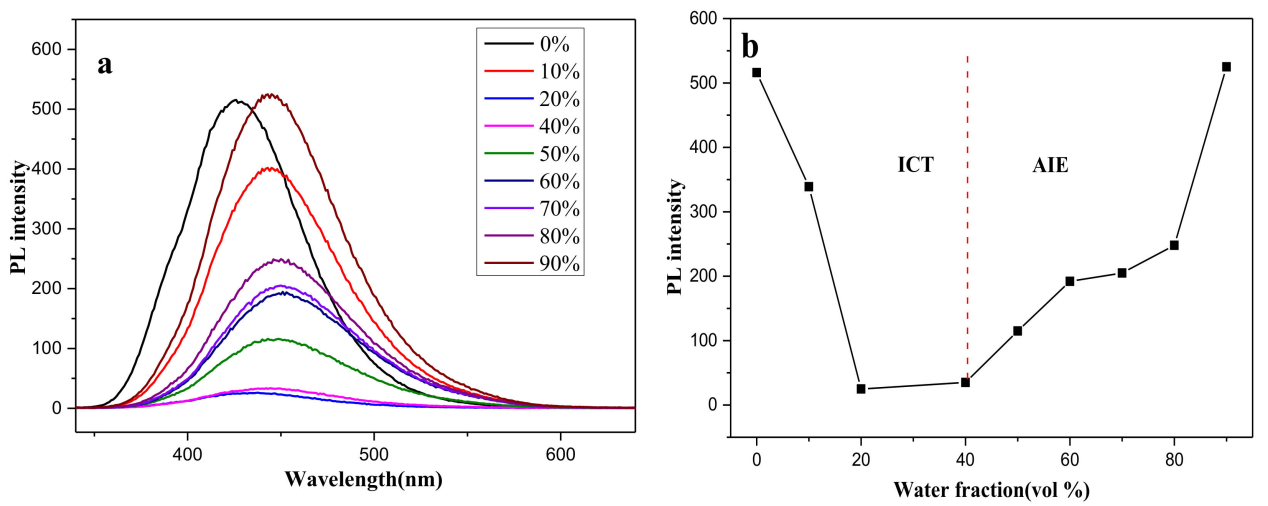

Figure 2. (a) PL spectra of 1a in THF/water mixtures with different water fractions $\left(f_{\mathrm{w}}\right)$; and (b) plot of peak intensity of 1 a versus $f_{\mathrm{W}}$ in the THF/water mixtures $\left(10^{-5} \mathrm{~mol} \cdot \mathrm{L}^{-1}\right.$, excitation wavelength: $\left.322 \mathrm{~nm}\right)$.

Such AIE properties were also confirmed by the vivid image of the solid powders under $365 \mathrm{~nm}$ UV illumination, as depicted in Figure 3. The solid powder and 1a dissolved in toluene emitted strong blue fluorescence. Conversely, the emission spectra of the solution and film samples were different, considering the broad emission peaks and red shift in Figure 3. Compound 1a exhibited dual-state emission behaviors and that demonstrated its fluorescence was strong in both solution and the aggregated state.

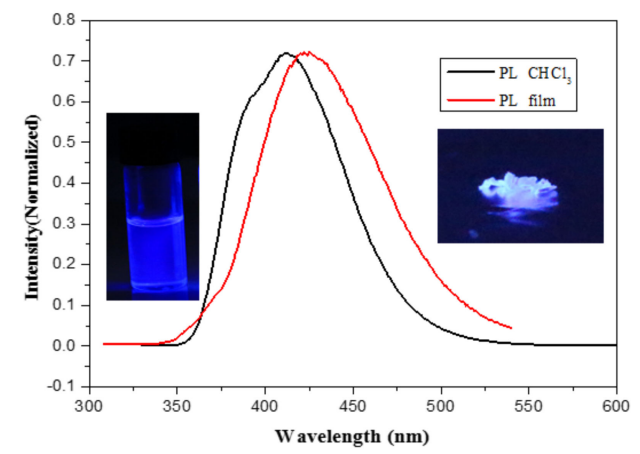

Figure 3. PL spectra of 1a. Inset are photographs of ground powder of 1a and 1a in toluene under $365 \mathrm{~nm}$ illumination. 


\subsection{The Electrochemical Properties of $\mathbf{1 a - c}$}

The electrochemical properties of $\mathbf{1 a}-\mathbf{c}$ in $\mathrm{CHCl}_{3}$ were investigated by $\mathrm{CV}$. The electrochemical data are summarized in Table 1. Figure 4 displays representative $C V$ traces for the oxidation and reduction of 1a, demonstrating that 1a undergoes a quasi-reversible reduction at the cathodic potential associated with the reduction of the electron-deficient sulfone moiety to form an anion radical. Compound 1a also exhibits an irreversible oxidation process corresponding to the removal of electrons from the terminal alkoxy phenyl group to form a radical cation.

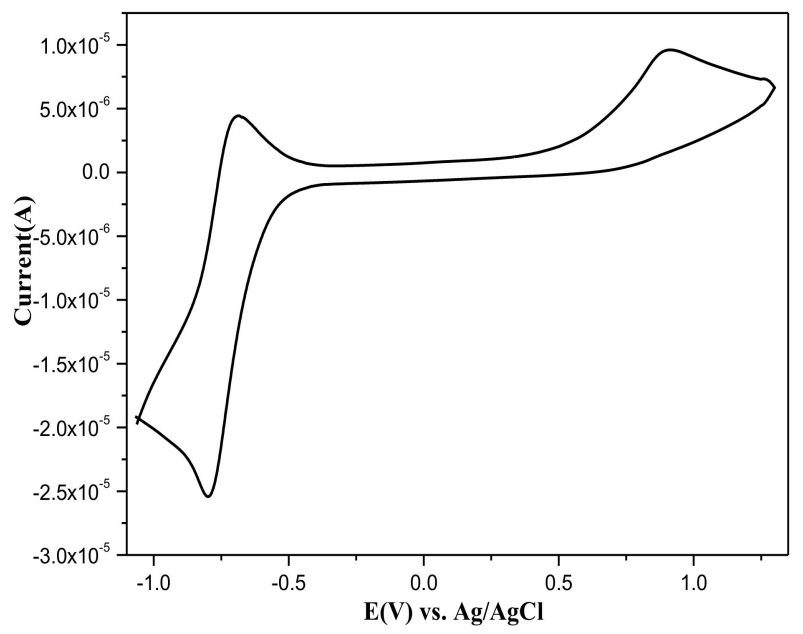

Figure 4. Cyclic voltammograms of $\mathbf{1 a}$ in $\mathrm{CHCl}_{3}\left(1 \times 10^{-3} \mathrm{M}\right)$.

Table 1. Photophysical, physical, and electrochemical data for $\mathbf{1 a - c .}$

\begin{tabular}{|c|c|c|c|c|c|c|c|c|}
\hline Comp. & $\begin{array}{c}{ }^{\mathrm{a}} \lambda_{\max , \mathrm{Abs}} \\
(\mathrm{nm})\end{array}$ & $\begin{array}{c}{ }^{a} \lambda_{\text {max,em }} \\
(\mathrm{nm})\end{array}$ & $\begin{array}{c}\mathrm{b} \lambda_{\text {max,em }} \\
(\mathrm{nm})\end{array}$ & ${ }^{\mathrm{c}} \Phi_{\mathbf{F}}$ & $\begin{array}{c}\text { E }^{\text {red/peak }} \\
\text { (V) }\end{array}$ & $\begin{array}{c}E_{1} \text { ox/peak } \\
\text { (V) }\end{array}$ & $\begin{array}{c}{ }^{\mathrm{d}} E_{\mathrm{g}}{ }^{\text {opt }} \\
(\mathrm{eV})\end{array}$ & $\begin{array}{c}{ }^{\mathrm{e}} \mathrm{T}_{\mathrm{g}} / \mathrm{T}_{5 \mathrm{~d}} \\
\left.{ }^{\circ} \mathrm{C}\right)\end{array}$ \\
\hline $1 a$ & 323 & 412 & 420 & 0.42 & -0.73 & 0.62 & 4.18 & $119 / 396$ \\
\hline $1 b$ & 326 & 411 & 423 & 0.36 & -0.74 & 0.75 & 4.21 & $156 / 383$ \\
\hline 1c & 328 & 411 & 423 & 0.32 & -0.76 & 0.78 & 4.26 & $145 / 386$ \\
\hline
\end{tabular}

${ }^{\text {a }}$ Measured in $\mathrm{CHCl}_{3} .{ }^{\mathrm{b}}$ Measured for film. ${ }^{\mathrm{c}}$ Measured in $\mathrm{CHCl}_{3}$ with quinine sulfate as a standard (QY = 0.54) [17].

${ }^{\mathrm{d}}$ Calculated using $E \mathrm{Eg}=1240 / \lambda^{\mathrm{abs}}$ onset. ${ }^{\mathrm{e}}$ Analyzed by DSC $/ \mathrm{TGA}$ at a heating rate of $10{ }^{\circ} \mathrm{C} \cdot \mathrm{min}^{-1}$ under $\mathrm{N}_{2}$.

\subsection{Theoretical Calculations}

All calculations were carried out using the Gaussian 09 package [18]. Calculations of the electronic ground state of compound 1a-c were carried out using density functional theory (DFT) [19] with the B3LYP exchange-correlation functional $[20,21]$ together with the $6-31 \mathrm{G}$ basis set [22]. GaussView 5.0.8 was used to calculate the interface of the structures and manipulate orbital.

DFT was used to calculate molecular orbitals to understand the photophysical behavior of the synthesized compounds. To estimate the charge-carrier injection barriers, we investigated the changes that occurred upon frontier orbital substitution. Figure 5 shows the highest occupied molecular orbital (HOMO), lowest unoccupied molecular orbital (LUMO) and energy gap ( $\left.E_{\mathrm{g}}\right)$ of $\mathbf{1 a}$ in toluene, THF and DMSO. The electron density distributions of representative 1a change considerably between the HOMO and LUMO. The electron density distributions of the HOMO are mostly located over the alkoxy benzene groups, whereas the LUMOs are mainly concentrated on the sulfone core. $E_{\mathrm{g}}$ between the HOMO and LUMO decreases from 4.03 to $3.97 \mathrm{eV}$ from toluene to DMSO, which is consistent with the slight red shift of $1 \mathrm{~nm}$ of the UV-vis absorption peak in polar solvents. Generally, this type of dye molecule with such an electron distribution indicates ICT character, which is consistent with the experimental results. 


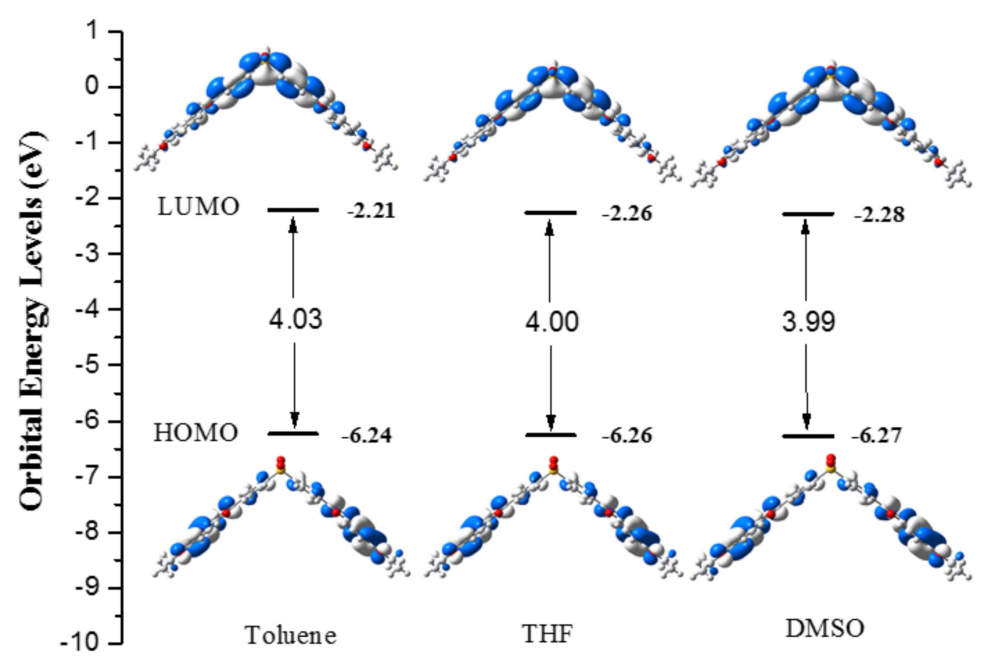

Figure 5. Electron density contours and orbital energies calculated for the HOMO and LUMO of 1a at the Beck3LYP/DZP level in toluene, THF and DMSO.

The calculated vertical ionization potential $\operatorname{IP}\left(\operatorname{IP}_{\mathrm{v}}\right)$, adiabatic IP $\left(\mathrm{IP}_{\mathrm{a}}\right)$, vertical electron affinity $\left(E A_{v}\right)$, and adiabatic electron affinity $\left(E A_{a}\right)$ for $1 \mathbf{a}$ are listed in Table 2. The reorganization energy $(\lambda)$ can be used to estimate the charge transport rate and balance between holes and electrons; these results are also provided in Table 2. The reorganization energy for electron transport can be expressed in terms of the electron extraction potential (EEP): $\lambda_{\mathrm{e}}=\mathrm{EEP}-\mathrm{EA}_{\mathrm{v}}$. EEP represents the electron extraction potential, which is the energy difference between $\mathrm{M}$ and $\mathrm{MM}$ - (anionic) when considering M-. It was found that representative $1 \mathrm{a}$ had a low $\lambda_{\mathrm{e}}$ value of 0.28 , which is similar to that of tris(8-hydroxyquinolinato)aluminum $\left(\lambda_{\mathrm{e}}=0.276\right)$ [23] and good electron transfer ability. These results indicate that 1a may be a promising electron transport material.

Table 2. Ionization potentials, electron affinities, extraction potentials, internal reorganization energies, and $\Delta=\left|\lambda_{\mathrm{h}}-\lambda_{\mathrm{e}}\right|$ (in $\mathrm{eV}$ ) for the studied complexes.

\begin{tabular}{cccccccccc}
\hline Comp. & IP (v) & IP (a) & HEP & EA (v) & EA (a) & EEP & $\lambda_{\text {hole }}$ & $\lambda_{\text {electron }}$ & $\Delta$ \\
\hline $\mathbf{1 a}$ & 6.21 & 6.07 & 5.90 & 2.35 & 2.49 & 2.63 & 0.31 & 0.28 & 0.03 \\
$\mathbf{1 b}$ & 6.18 & 6.07 & 5.90 & 2.29 & 2.49 & 2.63 & 0.28 & 0.34 & 0.06 \\
$\mathbf{1 c}$ & 6.17 & 6.07 & 5.90 & 2.29 & 2.49 & 2.63 & 0.27 & 0.34 & 0.07 \\
Alq $_{3}$ & IP (5.8) & & & EA (3.0) & & & 0.242 & 0.276 & 0.034 \\
\hline
\end{tabular}

The thermal properties of $\mathbf{1 a - c}$ were evaluated by thermal gravimetric analysis (TGA) and differential scanning calorimetry (DSC) under nitrogen atmosphere. (Table 1 and Figure S4). The TGA revealed that the compounds possessed relatively high thermal stability with an initial weight loss (5\%) temperature of $383-396^{\circ} \mathrm{C}$. The glass transition temperatures of $\mathbf{1 a}-\mathbf{c}$, as shown in Table 1 , were $119{ }^{\circ} \mathrm{C}, 156^{\circ} \mathrm{C}$ and $145^{\circ} \mathrm{C}$, respectively. The excellent thermal stability of $\mathbf{1 a}-\mathbf{c}$ should aid the formation of amorphous films.

\section{Experimental}

\section{General Information}

Ultraviolet-visible (UV-vis) spectra were recorded on a Lambda 25 spectrophotometer. Fluorescence spectra were obtained using a Shimadzu RF-5301PC fluorescence spectrophotometer. Cyclic voltammetric studies were carried out using a $\mathrm{CHI} 852 \mathrm{C}$ instrument with $\mathrm{CHCl}_{3}$ as the solvent $\left(10^{-3} \mathrm{M}\right)$ and $0.1 \mathrm{M} \mathrm{Bu}_{4} \mathrm{NClO}_{4}$ as the supporting electrolyte. Counter and working electrodes 
consisted of a Pt wire and glass carbon, respectively, and the reference electrode was $\mathrm{Ag} / \mathrm{AgCl}$. The thermal stability of the target compounds was characterized using a Shimadzu DTG-60H thermogravimetric analyzer.

Starting compound 2 and p,p'-Dihydrazinocarbonyl diphenylsulfone (3) were synthesized according to literature method [13].

Representative procedure for the synthesis of 1a-c: A mixture of compound $2(2.2 \mathrm{mmol})$, $\mathrm{p}, \mathrm{p}^{\prime}$-Dihydrazinocarbonyl diphenylsulfone $(1 \mathrm{mmol})$, and phosphorous oxychloride $(8 \mathrm{~mL})$ was heated at reflux for $8 \mathrm{~h}$, and then poured onto crushed ice after cooling to room temperature. The white solid was obtained. The crude product was separated on a flash silica gel column $\left(\mathrm{CHCl}_{2} / \mathrm{Ethyl}\right.$ acetate $)$ to afford 1a-c.

p,p'-Bis[2-(4-Ethoxyphenyl)-1,3,4-oxadiazol-5-yl]diphenylsulfone (1a): White powder, yield: 40\%. $\mathrm{Mp} 329^{\circ} \mathrm{C}$ (DSC). ${ }^{1} \mathrm{H}-\mathrm{NMR}\left(400 \mathrm{MHz}, \mathrm{CDCl}_{3}\right): \delta(\mathrm{ppm}) 1.44(\mathrm{t}, J=7.2 \mathrm{~Hz}, 6 \mathrm{H}), 4.11(\mathrm{q}, J=7.2 \mathrm{~Hz}, 4 \mathrm{H})$, $7.01(\mathrm{~d}, J=8.8 \mathrm{~Hz}, 4 \mathrm{H}), 8.04(\mathrm{~d}, J=9.0 \mathrm{~Hz}, 4 \mathrm{H}), 8.12(\mathrm{~d}, J=9.0 \mathrm{~Hz}, 4 \mathrm{H}), 8.27(\mathrm{~d}, J=8.8 \mathrm{~Hz}, 4 \mathrm{H}) ;{ }^{13} \mathrm{C}-\mathrm{NMR}$ $\left(100 \mathrm{MHz}, \mathrm{CDCl}_{3}\right): \delta$ (ppm) 14.65, 63.85, 115.12, 115.61, 127.67, 128.60, 128.79, 128.94, 143.37, 162.21, 162.51, 165.45; FTIR $\left(\mathrm{KBr}, \mathrm{cm}^{-1}\right): 3079,2920,1615,1489,1066,842$; TOF-Ms $(m / z)[\mathrm{M}+\mathrm{H}]^{+}=596.1648$; Anal. Calcd for $\mathrm{C}_{32} \mathrm{H}_{26} \mathrm{~N}_{4} \mathrm{O}_{6} \mathrm{~S}$ : C, 64.64. $\mathrm{H}$, 4.41. Found: $\mathrm{C}, 64.71$. $\mathrm{H}, 4.48$.

p,p'-Bis[2-(4-Butoxyphenyl)-1,3,4-oxadiazol-5-yl]diphenylsulfone (1b): White powder, yield: $43 \%$. Mp $325{ }^{\circ} \mathrm{C}$ (DSC). ${ }^{1} \mathrm{H}-\mathrm{NMR}\left(400 \mathrm{MHz}, \mathrm{CDCl}_{3}\right): \delta(\mathrm{ppm}) 0.98(\mathrm{t}, J=7.2 \mathrm{~Hz}, 6 \mathrm{H}) .1 .52(\mathrm{~m}, 4 \mathrm{H}), 1.79(\mathrm{~m}, 4 \mathrm{H}), 4.03$ $(\mathrm{t}, J=6.4 \mathrm{~Hz} 4 \mathrm{H}), 7.01(\mathrm{~d}, J=8.8 \mathrm{~Hz}, 4 \mathrm{H}), 8.04(\mathrm{~d}, J=8.8 \mathrm{~Hz}, 4 \mathrm{H}), 8.13(\mathrm{~d}, J=8.8 \mathrm{~Hz}, 4 \mathrm{H}), 8.28(\mathrm{~d}, J=8.8 \mathrm{~Hz}$, $4 \mathrm{H}) ;{ }^{13} \mathrm{C}-\mathrm{NMR}\left(100 \mathrm{MHz}, \mathrm{CDCl}_{3}\right): \delta$ (ppm) 13.79, 19.19, 31.14, 68.06, 115.14, 115.54, 127.67, 128.60, 128.80,

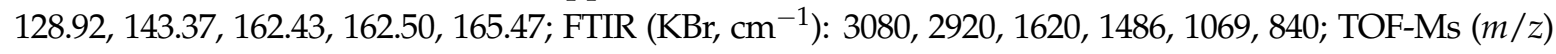
$[\mathrm{M}+\mathrm{H}]^{+}=651.1227$; Anal. Calcd for $\mathrm{C}_{36} \mathrm{H}_{34} \mathrm{~N}_{4} \mathrm{O}_{6} \mathrm{~S}: \mathrm{C}, 66.45$. H, 5.27. Found: $\mathrm{C}, 66.46 . \mathrm{H}, 5.34$.

p,p'-Bis[2-(4-Hexoxyphenyl)-1,3,4-oxadiazol-5-yl]diphenylsulfone (1c): White powder, yield: $22 \%$. Mp $282{ }^{\circ} \mathrm{C}(\mathrm{DSC}) .{ }^{1} \mathrm{H}-\mathrm{NMR}\left(400 \mathrm{MHz}, \mathrm{CDCl}_{3}\right): \delta(\mathrm{ppm}) 0.91(\mathrm{t}, J=7.2 \mathrm{~Hz}, 6 \mathrm{H}), 1.38(\mathrm{~m}, 24 \mathrm{H})$, $1.83(\mathrm{~m}, 4 \mathrm{H}), 4.05(\mathrm{t}, J=6.4 \mathrm{~Hz}, 4 \mathrm{H}), 7.03(\mathrm{~d}, J=8.8 \mathrm{~Hz}, 4 \mathrm{H}), 8.06(\mathrm{~d}, J=8.8 \mathrm{~Hz}, 4 \mathrm{H}), 8.14(\mathrm{~d}, J=8.8 \mathrm{~Hz}$, $4 \mathrm{H}), 8.29(\mathrm{~d}, J=8.8 \mathrm{~Hz}, 4 \mathrm{H}) ;{ }^{13} \mathrm{C}-\mathrm{NMR}\left(100 \mathrm{MHz}, \mathrm{CDCl}_{3}\right): \delta(\mathrm{ppm}) 14.04,22.63,25.72,29.12,31.59$, 68.44, 115.20, 115.59, 127.73, 128.67, 128.87, 128.98, 143.42, 162.49, 165.54; FTIR $\left(\mathrm{KBr}, \mathrm{cm}^{-1}\right)$ : 3080, 2924, 1622, 1486, 1069, 844; TOF-Ms $(m / z)[\mathrm{M}+\mathrm{H}]^{+}=707.1256$; Anal. Calcd for $\mathrm{C}_{40} \mathrm{H}_{42} \mathrm{~N}_{4} \mathrm{O}_{6} \mathrm{~S}: \mathrm{C}, 67.97, \mathrm{H}$, 5.99. Found: C, 67.99. H, 6.03.

\section{Conclusions}

A series of D- $\pi$-A- $\pi$-D type sulfone derivatives with alkoxy D groups and sulfone A units was produced. The experimental results demonstrate that these V-shaped compounds display the features of both ICT and AIE. These blue emitters are solution processible and exhibit good film-forming ability and high thermal stability, marking them promising as electron transport materials.

Supplementary Materials: Figures S1-S4: Characterization of compounds 1a-c, Figure S5: Absorption spectra of 1a-c, Figure S6: PL emission spectra of $\mathbf{1 b}$, Figure S7: PL emission spectra of $\mathbf{1 a}, \mathbf{1} \mathbf{b}$ in $\mathrm{DMF} / \mathrm{H}_{2} \mathrm{O}$ mixtures, Figure S8: Cyclic voltammograms of 1a, Figure S9: Electron density contours and orbital energies calculated for the HOMOs and LUMOs of $\mathbf{1 b}, \mathbf{1 c}$.

Author Contributions: Study design, data analysis and writing manuscript, R.H.; Literature search, data analysis and manuscipt modification, B.Z.; Data collection and data analysis, manuscript modification, Y.X.; Study design, direct and writing, D.L.

Funding: This research was funded by [the National Science Foundation of China] grant number [21442004 and 201502008] and [the National Natural Science Foundation of Jilin Province] grant number [20101548].

Acknowledgments: This work was supported by the National Science Foundation of China (Nos. 21442004 and 201502008) and the National Natural Science Foundation of Jilin Province (grant No. 20101548).

Conflicts of Interest: The authors declare no conflict of interest. 


\section{References}

1. Burroughes, J.H.; Bradley, D.D.C.; Brown, A.R.; Marks, R.N.; Mackay, K.; Friend, R.H.; Burn, P.L.; Holmes, A.B. Light-emitting diodes based on conjugated polymers. Nature 1990, 347, 539-541. [CrossRef]

2. Yang, Y.M.; Zhao, Q.; Feng, W.; Li, F.Y. Luminescent chemodosimeters for bioimaging. Chem. Rev. 2013, 113, 192-270. [CrossRef] [PubMed]

3. Xu, B.J.; Wu, H.Z.; Chen, J.R.; Yang, Z.; Yang, Z.Y.; Wu, Y.C.; Zhang, Y.; Jin, C.J.; Lu, P.Y.; Chi, Z.G.; et al. White-light emission from a single heavy atom-free molecule with room temperature phosphorescence, mechanochromism and thermochromism. Chem. Sci. 2017, 8, 1909-1914. [CrossRef] [PubMed]

4. Zhang, B.; Ge, C.; Yao, J.; Liu, Y.; Xie, H.; Fang, J. Selective selenol fluorescent probes: Design, synthesis, structural determinants, and biological applications. J. Am. Chem. Soc. 2015, 137, 757-769. [CrossRef]

5. Tang, Y.; Jin, L.; Yin, B. A dual-selective fluorescent probe for GSH and Cys detection: Emission and $\mathrm{pH}$ dependent selectivity. Anal. Chim. Acta 2017, 993, 87-95. [CrossRef] [PubMed]

6. Jenekhe, S.A.; Osaheni, J.A. Excimers and exciplexes of conjugated polymers. Science 1994, 265, 765-768. [CrossRef] [PubMed]

7. Luo, D.X.; Li, X.L.; Zhao, Y.; Gao, Y.; Liu, B.Q. High-Performance Blue Molecular Emitter-Free and Doping-Free Hybrid White Organic Light-Emitting Diodes: An Alternative Concept to Manipulate Charges and Excitons Based on Exciplex and Electroplex Emission. ACS Photonics 2017, 4, 1566-1575. [CrossRef]

8. Luo, D.X.; Yang, Y.F.; Xiao, Y.; Zhao, Y.; Yang, Y.B.; Liu, B.Q. Regulating Charge and Exciton Distribution in High-Performance Hybrid White Organic Light-Emitting Diodes with n-Type Interlayer Switch. Nano-Micro Lett. 2017, 9, 37. [CrossRef]

9. Tang, B.Z.; Zhan, X.W.; Yu, G.; Lee, P.P.S.; Liu, Y.Q.; Zhu, D.B. Efficient blue emission from siloles. J. Mater. Chem. 2001, 11, 2974-2978. [CrossRef]

10. Liu, B.Q.; Nie, H.; Lin, G.W.; Hu, S.B.; Gao, D.Y.; Zou, J.H.; Xu, M.; Wang, L.; Zhao, Z.J.; Ning, H.L.; et al. High-Performance Doping-Free Hybrid White OLEDs Based on Blue Aggregation-Induced Emission Luminogens. ACS Appl. Mater. Interfaces 2017, 9, 34162-34171. [CrossRef] [PubMed]

11. Liu, B.Q.; Nie, H.; Zhou, X.B.; Hu, S.B.; Luo, D.X.; Gao, D.Y.; Zou, J.H.; Xu, M.; Wang, L.; Zhao, Z.J.; et al. Manipulation of Charge and Exciton Distribution Based on Blue Aggregation-Induced Emission Fluorophors: A Novel Concept to Achieve High-Performance Hybrid White Organic Light-Emitting Diodes. Adv. Funct. Mater. 2016, 26, 776-783. [CrossRef]

12. Mei, J.; Leung, L.C.; Ryan, T.K.; Kwok, R.T.K.; Lam, W.Y.; Tang, B.Z. Aggregation-Induced Emission: Together We Shine, United We Soar! Chem. Rev. 2015, 115, 11718-11940. [CrossRef] [PubMed]

13. Gu, P.Y.; Zhang, Y.H.; Liu, G.Y.; Ge, J.F.; Xu, Q.F.; Zhang, Q.C.; Lu, J.M. A new V-shaped organic fluorescent compound integrated with crystallization-induced emission enhancement and intramolecular charge transfer. Chem. Asian J. 2013, 8, 2161-2166. [CrossRef] [PubMed]

14. Shao, A.D.; Guo, Z.Q.; Zhu, S.J.; Zhu, S.Q.; Shi, P.; Tian, H.; Zhu, W.H. Insight into aggregation-induced emission characteristics of red-emissive quinoline-malononitrile by cell tracking and real-time trypsin detection. Chem. Sci. 2014, 5, 1383-1389. [CrossRef]

15. Gu, P.Y.; Lu, C.J.; Hu, Z.J.; Li, N.J.; Zhao, T.T.; Xu, Q.F.; Xu, Q.H.; Zhang, J.D.; Lu, J.M. The AIEE effect and two-photon absorption (TPA) enhancement induced by polymerization: Synthesis of a monomer with ICT and AIE effects and its homopolymer by ATRP and a study of their photophysical properties. J. Mater. Chem. C 2013, 1, 2599-2606. [CrossRef]

16. Qin, W.; Ding, D.; Liu, J.Z.; Yuan, W.Z.; Hu, Y.; Liu, B.; Tang, B.Z. Biocompatible nanoparticles with aggregation-induced emission characteristics as far-red/near-infrared fluorescent bioprobes for in vitro and in vivo imaging applications. Adv. Funct. Mater. 2012, 22, 771-779. [CrossRef]

17. Kartens, T.; Kobs, K. Rhodamine B and rhodamine 101 as reference substances for fluorescence quantum yield measurements. J. Phys. Chem. 1980, 84, 1871-1872. [CrossRef]

18. Frisch, M.J.; Trucks, G.W.; Schlegel, H.B.; Scuseria, G.E.; Robb, M.A.; Cheeseman, J.R.; Scalmani, G.; Barone, V.; Mennucci, B. Fox, GAUSSIAN 09 (Revision B.01); Gaussian, Inc.: Wallingford, UK, 2010.

19. Hohenberg, P.; Kohn, W. Inhomogeneous Electron Gas. Phys. Rev. 1964, 136, B864-B871. [CrossRef]

20. Lee, C.; Yang, W.T.; Parr, R.G. Development of the Colle-Salvetti correlation-energy formula into a functional of the electron density. Phys. Rev. B 1988, 37, 785-789. [CrossRef] 
21. Becke, A.D. Density-functional thermochemistry. III. The role of exact exchange. J. Chem. Phys. 1993, 98, 5648-5652. [CrossRef]

22. Hariharan, P.C.; Pople, J.A. Accuracy of AH $n$ equilibrium geometries by single determinant molecular orbital theory. Mol. Phys. 1974, 27, 209-214. [CrossRef]

23. Lin, B.C.; Cheng, C.P.; You, Z.Q.; Hsu, C.P. Charge Transport Properties of Tris(8-hydroxyquinolinato) aluminum(III): Why It Is an Electron Transporter. J. Am. Chem. Soc. 2005, 127, 66-67. [CrossRef]

Sample Availability: Samples of the compounds are available from the authors.

(C) 2018 by the authors. Licensee MDPI, Basel, Switzerland. This article is an open access article distributed under the terms and conditions of the Creative Commons Attribution (CC BY) license (http://creativecommons.org/licenses/by/4.0/). 